\title{
Blended Cement Systems with Zeolitized Silica Fume
}

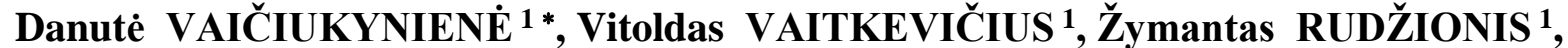 Vilimantas VAIČIUKYNAS ${ }^{2}$, Arūnas Aleksandras NAVICKAS ${ }^{1}$, Dalia NIZEVIČIENE் ${ }^{3}$}

\author{
${ }^{1}$ Faculty of Civil Engineering and Architecture, KTU, Studentu str. 48, LT-51367 Kaunas, Lithuania \\ ${ }^{2}$ Faculty of Water and Land Management, ASU, Universiteto str. 10, LT-53361, Akademija, Kauno distr., Lithuania \\ ${ }^{3}$ Faculty of Electrical and Electronics Engineering, KTU, Studentu str. 48, LT-51367 Kaunas, Lithuania \\ cross'ref http://dx.doi.org/10.5755/j01.ms.22.2.7018
}

\section{Received 29 April 2014; accepted 24 February 2015}

\begin{abstract}
In this paper the properties and the hydration of Portland cement pastes containing zeolitized silica fume were studied. Hydrosodalite was obtained by zeolitization of silica fume. XRD, DSC, SEM and energy-dispersive X-ray spectroscopy were used as investigation methods. The compressive strength of hardened cement paste was measured after 28 days. The levels of cement replacement by additives were $5 \%, 10 \%$ and $15 \%$ by weight in the specimens. Changes in the strength of hardened cement paste were observed. The influence of additives on hydration rate and hydration temperature was also observed. Both $1 \mathrm{Hs}$ (hydrosodalite) and $2 \mathrm{Hs}$ (modified hydrosodalite) additives accelerate the hydration of the cement paste. The highest hydration temperature was achieved in a mixture with $5 \mathrm{wt}$. \% 1Hs additive and with $10 \mathrm{wt}$. \% $2 \mathrm{Hs}$ additive. The microstructure of hardened cement paste specimens with $1 \mathrm{Hs}$ and $2 \mathrm{Hs}$ additive is denser compared with reference specimens without the additives. The maximum compressive strength of the specimens with $10 \mathrm{wt}$. \% of $2 \mathrm{Hs}$ reached up to $101 \mathrm{MPa}$ under laboratory conditions.
\end{abstract}

Keywords: zeolitized silica fume, cement hydration, hydrosodalite.

\section{INTRODUCTION}

Zeolites are crystalline aluminosilicates, which have large quantities of reactive $\mathrm{SiO}_{2}$ and $\mathrm{Al}_{2} \mathrm{O}_{3}$. It has been used in producing blended cements and concretes. Like other pozzolanic materials such as silica fume and fly ash, zeolite contributes to concrete strength mainly through the pozzolanic reaction with $\mathrm{Ca}(\mathrm{OH})_{2}$. These results are compared with those obtained from similar blended cement pastes prepared with silica fume and fly ash replacements. Supposedly C.S. Poon et al. [1,2] have showed that pozzolanic effect of zeolite improved the microstructure of hardened cement paste and reduced the content of the harmful large pores, hence made concrete more impervious.

Cement mortars and concretes incorporating clinoptilolite (natural zeolite), silica fume and fly ash were investigated for changes in their physical and mechanical properties. It was found that additions of $10 \%$ clinoptilolite and $10 \%$ pozzolite (1:1 mixture of silica fume and fly ash) were optimal for improvement of the quality of the hardened products, giving $8 \%$ and $13 \%$ increases in flexural and compressive strength respectively. The specific pore volume of the mortars incorporating zeolite decreased between the $28^{\text {th }}$ and $180^{\text {th }}$ day to levels below the values for the reference composition [3, 4].

Zeolites additives in concrete increase the durability of concrete. This is due to pozzolanic reaction of zeolite with Portland cement resulting in reduction of the formed $\mathrm{Ca}(\mathrm{OH})_{2}$ opposite to the reference PC. Ettringite and alkali-silica reaction gel formation in the microstructure of the composite against sulfate attack was limited with the usage of zeolite, fly ash and ground granulated blast

\footnotetext{
* Corresponding author. Tel.: +370-37-300465; fax: +370-37-300454
}

E-mail address: danpal@ktu.lt (D. Vaičiukynienè) furnace slag [5]. Because zeolite is environmentally friendly, it could be a good substitute for silica fume and metakaolin. Using zeolites is more effective in enhancing the durability of concrete than lowering w/c ratio [6].

The enhanced sulfate resistance noted in the cement blended with either silica fume or fly ash indicates the usefulness of these cements in both sulfate and sulfate plus chloride environments. Maximum deterioration, due to sulfate attack, was noted in cement. The blending materials used were silica fume, slag, and calcium carbonate. Slag and calcium carbonate improve the sulfate resistance of ordinary Portland cement paste [7].

R. Snellings et al. [8] have reported that zeolites actively participate in the hydration processes of cement. Their activity in the early stage of hydration is based mainly on the large surface area of the particles while, in the later stages of activity, chemical reactions occur between the products of the hydration of cement and the soluble $\mathrm{SiO}_{2}$. It has been shown that in all cement pastes which contain zeolite additives, the quantity of portlandite is lower than that in pure cement paste or is even totally absent. Natural pozzolans can be activated in an alkaline environment to synthesize high performance cementitious construction materials. In the paper [10], the results show that pozzolan containing sodium clinoptilolite can be prepared up to high strength binder by heat treatment. Calcinations can impart disorder a constituent of pozzolan with no amorphous phase to prepare a binder. Recently many publications analyzing the performance of cementitious systems containing zeolite, silica fume as an active mineral additive have been published. However, no data was found about the effect of zeolite-like materials, made from silica fume, additive on the properties of cementitious system. The objective of the study is to investigate the effect of zeolite-like materials, made from silica fume, on the performance of cementions systems. 


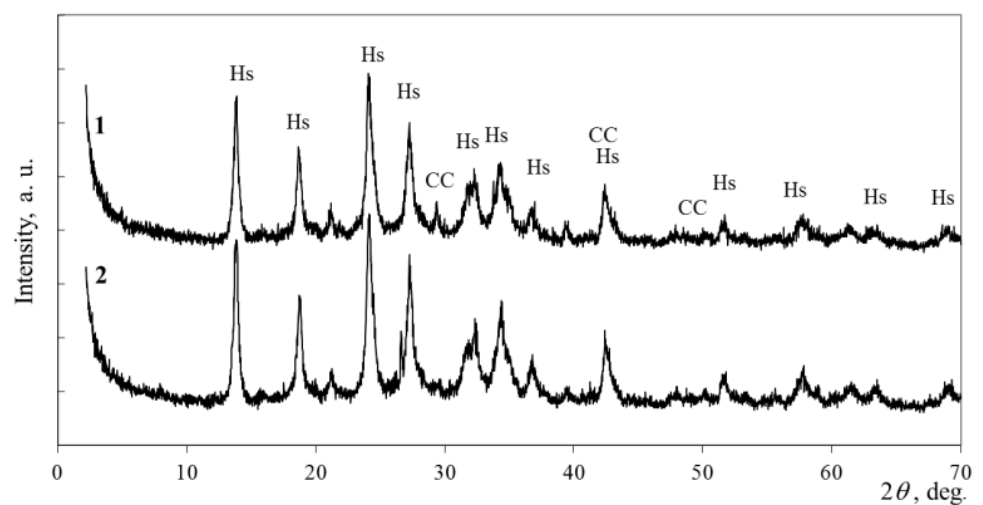

Fig. 1. The X-ray diffraction patterns of hydrosodalites: 1 -modified hydrosodalite (2Hs), 2 -pure hydrosodalite (1Hs); Note: Hshydrosodalite, $\mathrm{CC}$-calcium carbonate

\section{EXPERIMENTAL}

The Portland cement CEM I 42.R was used. Chemical composition of Portland cement and silica fume showed in Table 1. In this paper the hydration of two blended cement compositions were investigated, an OPC with $0,5,10$ and $15 \%$ of zeolite-like materials ( $1 \mathrm{Hs}$ and $2 \mathrm{Hs}$ ).

Table 1. Chemical composition of Portland cement, 1Hs, 2Hs and silica fume

\begin{tabular}{|c|c|c|c|c|}
\hline $\begin{array}{c}\text { Chemical } \\
\text { composition, }\end{array}$ & $\begin{array}{c}\text { Portland } \\
\text { cement }\end{array}$ & $1 \mathrm{Hs}$ & $2 \mathrm{Hs}$ & Silica fume \\
\hline $\mathrm{SiO}_{2}$ & 20.54 & 38.87 & 40.27 & 88 \\
\hline $\mathrm{Al}_{2} \mathrm{O}_{3}$ & 5.49 & 37.88 & 37.41 & 1.8 \\
\hline $\mathrm{Fe}_{2} \mathrm{O}_{3}$ & 3.52 & - & - & 1.8 \\
\hline $\mathrm{CaO}_{\mathrm{SO}_{3}}$ & 63.68 & - & 5.27 & 0.9 \\
\hline $\mathrm{Cl}^{-}$ & 0.95 & - & - & 0.9 \\
\hline $\mathrm{MgO}$ & 4.31 & - & - & 0.3 \\
\hline $\mathrm{K}_{2} \mathrm{O}$ & 0.52 & - & - & 1.8 \\
\hline $\mathrm{Na}_{2} \mathrm{O}$ & - & 23.25 & 17.05 & 2.0 \\
\hline $\mathrm{C}$ & - & - & - & 1.0 \\
\hline $\mathrm{C}_{3} \mathrm{~S}$ & 56.38 & - & - & - \\
\hline $\mathrm{C}_{2} \mathrm{~S}$ & 16.34 & - & - & - \\
\hline $\mathrm{C}_{3} \mathrm{~A}$ & 8.60 & - & - & - \\
\hline $\mathrm{C}_{4} \mathrm{AF}$ & 10.72 & - & - & - \\
\hline
\end{tabular}

The first additive is hydrosodalite (1Hs). This synthetic hydrosodalite was synthesized from: $\mathrm{NaOH}$, $\mathrm{Al}(\mathrm{OH})_{3}$ and silica fume $\left(\mathrm{SiO}_{2}\right.$ source $)$. The molar ratio of the raw material $\mathrm{Na}_{2} \mathrm{O}: \mathrm{Al}_{2} \mathrm{O}_{3}: \mathrm{SiO}_{2}: \mathrm{H}_{2} \mathrm{O}$ was 2:1:2:10. Low-temperature $\left(105^{\circ} \mathrm{C}\right)$ zeolite synthesis was performed in the unstirred suspension at 3 hours isothermal curing. The final product of synthesis was filtered, dried at $\sim 60{ }^{\circ} \mathrm{C}$ temperature and sieved through a $0.5 \mathrm{~mm}$-mesh sieve. The second additive (2Hs) was obtained by a modification of the first.

The X-ray curves of investigated samples before and after the modification were carried out. Both curves have a similar character and almost identical to visible peaks. The curves of X-ray diffraction analysis show that the diffraction peaks with interplanar distances (d) of 0.628 ; 0.363; 0.281; 0.256; 0.290; $0.174 \mathrm{~nm} \mathrm{(Fig.} \mathrm{1),} \mathrm{are}$ characteristic of hydrosodalite $(1 \mathrm{Hs})$. After ions exchange reaction the structure of hydrosodalite crystals was noticed to be stable because the shape of the X-ray diffraction patterns (Fig. 1, curve 2) did not change. Before modification crystalline phase consists $84.1 \%$ and $15.9 \%$ of amorphous phase is in the $1 \mathrm{Hs}$ material. After modification (2Hs) crystalline phase slightly decreases till $83.9 \%$ and an amorphous phase increases till $16.1 \%$. The chemical composition of $1 \mathrm{Hs}$ and $2 \mathrm{Hs}$ showed in Table 1.

The X-ray powder diffraction data were collected with DRON-6 X-ray diffractometer with Bragg-Brentano geometry using $\mathrm{Ni}$-filtered $\mathrm{Cu} \mathrm{K} \alpha$ radiation and graphite monochromator, operating with the voltage of $30 \mathrm{kV}$ and emission current of $20 \mathrm{~mA}$. The step-scan covered the angular range $2-70^{\circ}(2 \theta)$ in steps of $2 \theta=0.02^{\circ}$. Calculations of crystalline and amorphous phases was done with the EVA program. Thermal analysis (differential scanning calorimetry-DSC and thermogravimetry-TG) was also employed for measuring the thermal stability and phase transformation of products at a heating rate of $15^{\circ} \mathrm{C} / \mathrm{min}$, the temperature ranged from $30^{\circ} \mathrm{C}$ up to $1000{ }^{\circ} \mathrm{C}$ under the air atmosphere. The test was carried out on a Netzsch instrument STA 409 PC Luxx. The ceramic sample handlers and crucibles of Pt-Rh were used there. The structure of hardened cement paste was studied by scanning electronic microscopy. A high resolution scanning electron microscope FEI Quanta 200 FEG with a Schottky field emission gun (FEG). Chemical compositions of zeolite were investigated by an energydispersive X-ray spectrometer (EDS) with silicon type drift droplet detector. The cement paste hydration temperature measurements were performed with 8-channel USB TC-08 Thermocouple Data Logger (temperature measurement range from -270 to $+1820^{\circ} \mathrm{C}$ ). In all test sample constant flow was stable and the ratio of water and solid material was constant and equal to $\mathrm{W} / \mathrm{S}=0.3$. The contents of $1 \mathrm{Hs}$ or $2 \mathrm{Hs}$ were $0 ; 5 ; 10$ and $15 \%$ mass. Silica fume, $1 \mathrm{Hs}$ and $2 \mathrm{Hs}$ have surface areas of about $20.59 \mathrm{~m}^{2} / \mathrm{g}, 21.85 \mathrm{~m}^{2} / \mathrm{g}$ and $22.05 \mathrm{~m}^{2} / \mathrm{g}$ (Blaine), respectively. The formed test samples, $2 \times 2 \times 2 \mathrm{~cm}$ sized cubes, were hardened for 28 days. The test procedure of hardened cement paste compressive strength was applied according to the EN 196-1.

\section{RESULTS AND DISCUSSION}

\subsection{The effect of 1 Hs additive synthesized with silica fume on cement hydration}

$\mathrm{X}$-ray diffraction patterns of hardened cement paste specimens revealed that $\mathrm{Ca}(\mathrm{OH})_{2}$ decreased with the increase of $1 \mathrm{Hs}$ additive (Fig. 2). 


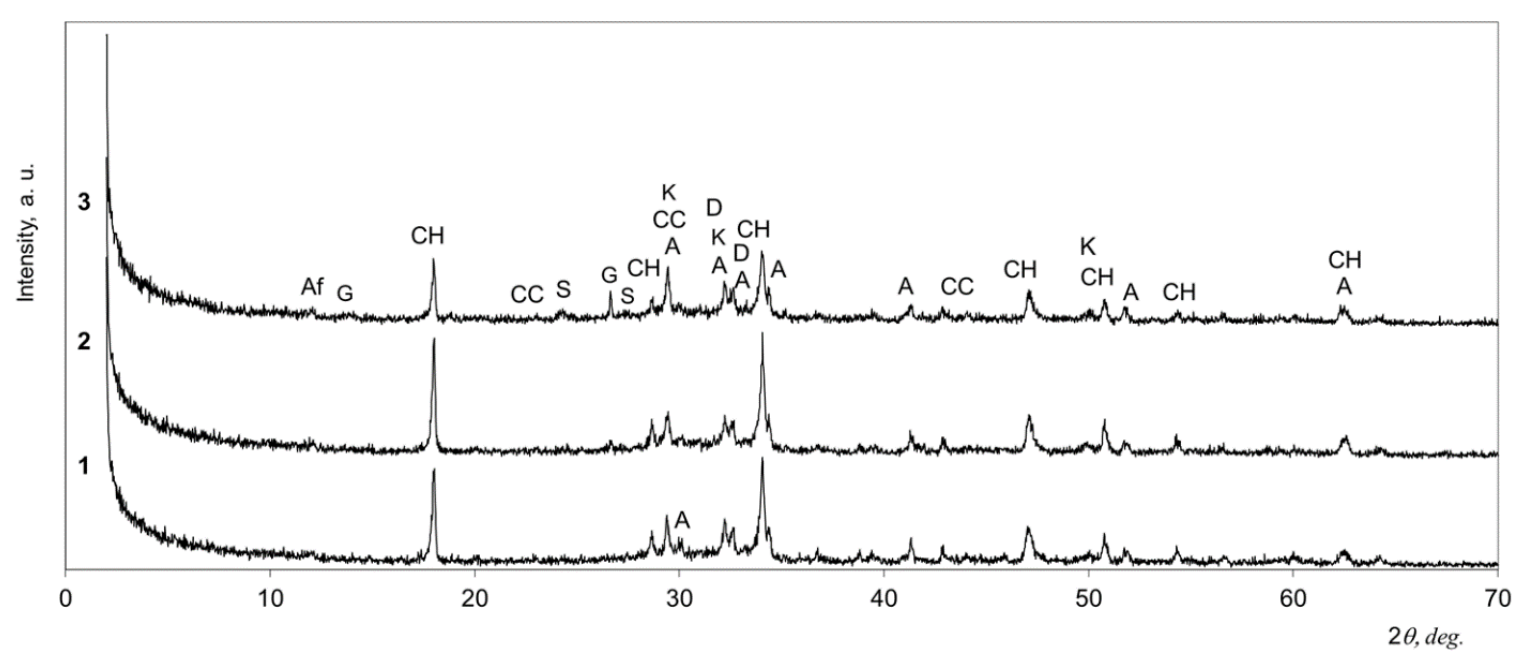

Fig. 2. X-ray diffraction patterns of hardened cement paste after after 28 days. 1Hs addition content accounts for $0 \%$ (1); $5 \%$ (2); $15 \%$ (3). Notes: $\mathrm{CH}$ - portlandite; $\mathrm{A}$-alite; $\mathrm{K}$-calcium silicate hydrate; $\mathrm{D}$ - belite; $\mathrm{E}$ - ettringite; $\mathrm{CC}$ - calcite; $\mathrm{G}$ - calcium aluminum silicate hidrate, $\mathrm{S}$ - sodium aluminum silicate hidrate, Af - monosulfoaluminate

The highest typical peak of $\mathrm{Ca}(\mathrm{OH})_{2}(0.493 \mathrm{~nm})$ is the most intense when the additive is not used by comparing three curves. After 28 days of hydration no hydrosodalite peaks were identified after 28 days of hydration. When zeolitic additive is present in the cement and water mixture, high $\mathrm{pH}$ of the zeolite causes disintegration and depolimerization of the aluminosilicate frame. During the depolimerization $\left[\mathrm{SiO}(\mathrm{OH})_{3}\right]^{-}$and $\left[\mathrm{Al}(\mathrm{OH})_{4}\right]^{-}$ions enter the solution and react with $\mathrm{Ca}^{2+}$ ions thus forming hydrated calcium silicates and calcium aluminates, very similar to those compounds, which develop during the hydration of ordinary cement [11].

Thermal analysis is an important expermental procedure used to study the cement hydration and comsumption of portandite due to pozzolanic reactions. TG and DSC curves of hardened cement paste with $1 \mathrm{Hs}$ are shown in Fig. 3. In the temperature range $173-$ $175^{\circ} \mathrm{C}$, and in the range up to $300{ }^{\circ} \mathrm{C}$ the complex dehydration of calcium silicates, aluminates and calcium aluminosilicates is observed. An endothermic peak in the temperature range $451-453{ }^{\circ} \mathrm{C}$ is attributed to decomposition of $\mathrm{Ca}(\mathrm{OH})_{2}$. This peak decreases with the increased amount of $1 \mathrm{Hs}$ (consumption of $\mathrm{Ca}(\mathrm{OH})_{2}$ by zeolite). In specimens with $1 \mathrm{Hs}$ the weight loss associated with $\mathrm{Ca}(\mathrm{OH})_{2}$ decomposition decreased till $3.12 \%$ after 28 days of hydration, compared with reference specimen without additive $(4.45 \%)$. This decrease of portlandite quantity can be attributed in particular to pozzolanic reactions. The result is the formation of calcium silicate hydration $(\mathrm{C}-\mathrm{S}-\mathrm{H})$ phases and aluminates. The last endothermic peak at $692-713{ }^{\circ} \mathrm{C}$ temperature is attributed to $\mathrm{CaCO}_{3}$ decomposition. The DTA curve of the tested specimens shows an exothermic peak at $744{ }^{\circ} \mathrm{C}$ temperature, which is typical of the recrystallization of $\mathrm{C}-$ $\mathrm{S}-\mathrm{H}(\mathrm{I})$.

These data confirm the argument that hydrosodalite and portlandite participate in pozzolanic reaction by forming secondary calcium silicate hydrates and hydro aluminates. It was found that $1 \mathrm{Hs}$ in the cement paste affect the temperature of hydration process. Higher hydration temperature intensifies the chemical reaction and the greater amount of heat is released during these reactions. Heat release curves are presented in Fig. 4.

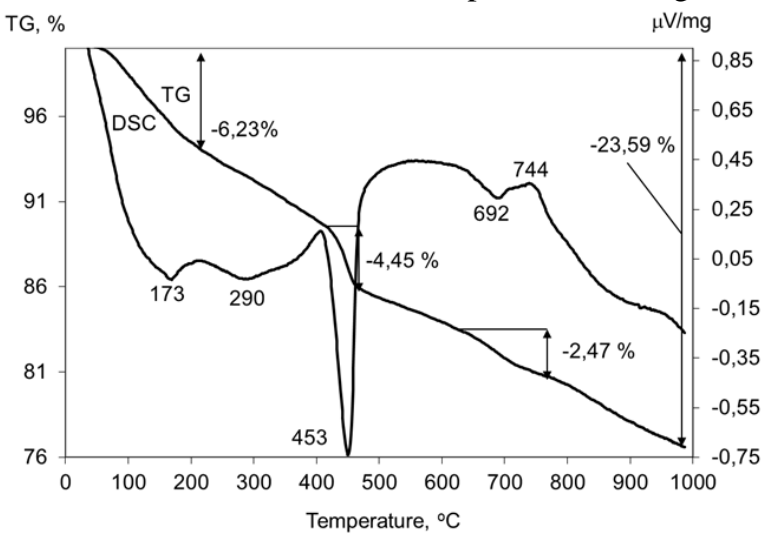

a

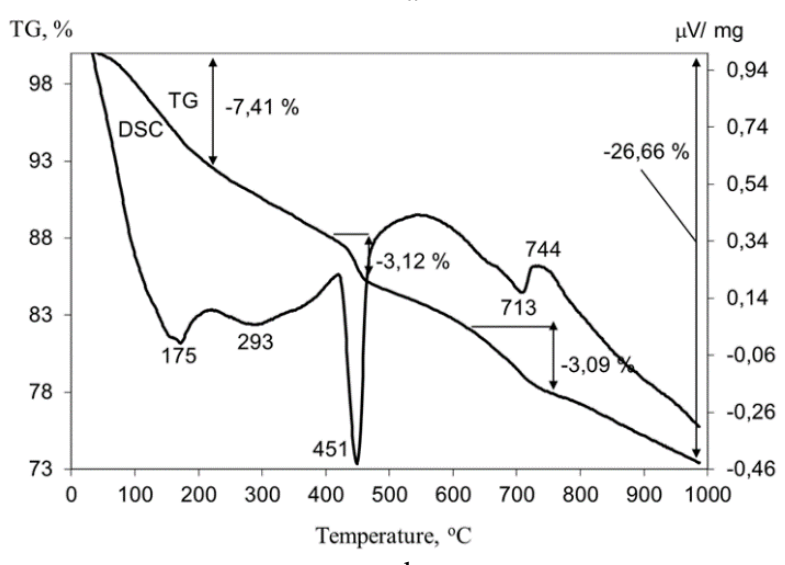

$\mathrm{b}$

Fig. 3. TG and DSC curves of hardened cement paste after 28 days. $1 \mathrm{Hs}$ addition content accounts for $0 \%$ (a) and $15 \%$ (b)

The hydration of cement paste was faster in all specimens with $1 \mathrm{Hs}(5,10$ and 15 wt. \% of cement). The hydration rate is a function of additive amount, i.e. the hydration rate increases with the higher additive content. The highest hydration temperature was observed in specimens where cement was replaced with 5 wt. \% of 1 Hs. 


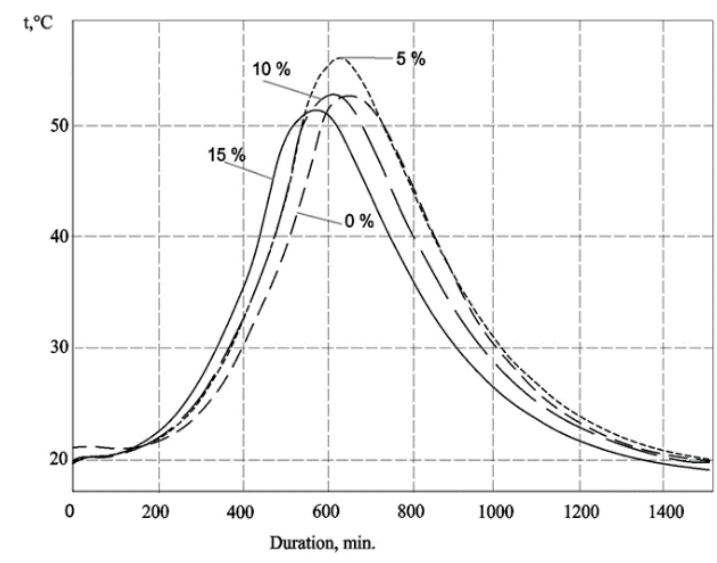

Fig. 4. The dependence of hydration temperature of cement paste on the quantity of $1 \mathrm{Hs}$

\subsection{The effect of $2 \mathrm{Hs}$ additive on cementitious system}

XRD patterns of hardened cement paste specimens with $2 \mathrm{Hs}$ additive are shown in Fig. 4. After 28 days of hydration, portlandite, calcium hydrosilicate, ettringite, non-hydrated alite, belite and the peaks of calcium carbonate, which forms when $\mathrm{CO}_{2}$ present in the ambient air reacts with calcium hydroxide, were identified. The intensity of portlandite peak decreases with the increase of additive as a result of pozzolanic reaction between $2 \mathrm{Hs}$ and $\mathrm{Ca}(\mathrm{OH})_{2}$. The endothermic effect observed in the thermogram (Fig. 6) at 108 and $155^{\circ} \mathrm{C}$ temperature is mainly due to the dehydration of $\mathrm{CSH}$ (tobermorite-like phase) as well as ettringite. Thus, the endothermic peak at $155^{\circ} \mathrm{C}$ temperature in the curve of this specimen may be specifically attributed to the high content of $\mathrm{C}-\mathrm{S}-\mathrm{H}$. From Fig. 6 it can be seen that the amount of C-S-H gel is the greatest when $2 \mathrm{Hs}$ additive is used, when compared to the specimen without additives or to specimens with $1 \mathrm{Hs}$ additive (Fig. 3).

The next endothermic peak at $289{ }^{\circ} \mathrm{C}$ is related to the dehydration of calcium silicate and calcium aluminosilicate hydrates. DSC curves of hardened cement paste show decomposition of $\mathrm{Ca}(\mathrm{OH})_{2}$ at $455^{\circ} \mathrm{C}$ temperature. After 28 days of hardening, $\mathrm{Ca}(\mathrm{OH})_{2}$ decomposition peak was weaker (Fig. 6) in specimens containing $15 \mathrm{wt} \%$ of $2 \mathrm{Hs}$ additive compared to the control specimen without additives (Fig. 3). The endothermic peaks at $706{ }^{\circ} \mathrm{C}$ indicate $\mathrm{CaCO}_{3}$ decomposition and the exothermic peak at $727^{\circ} \mathrm{C}$ is typical of the recrystallization of $\mathrm{C}-\mathrm{S}-\mathrm{H}(\mathrm{I})$.

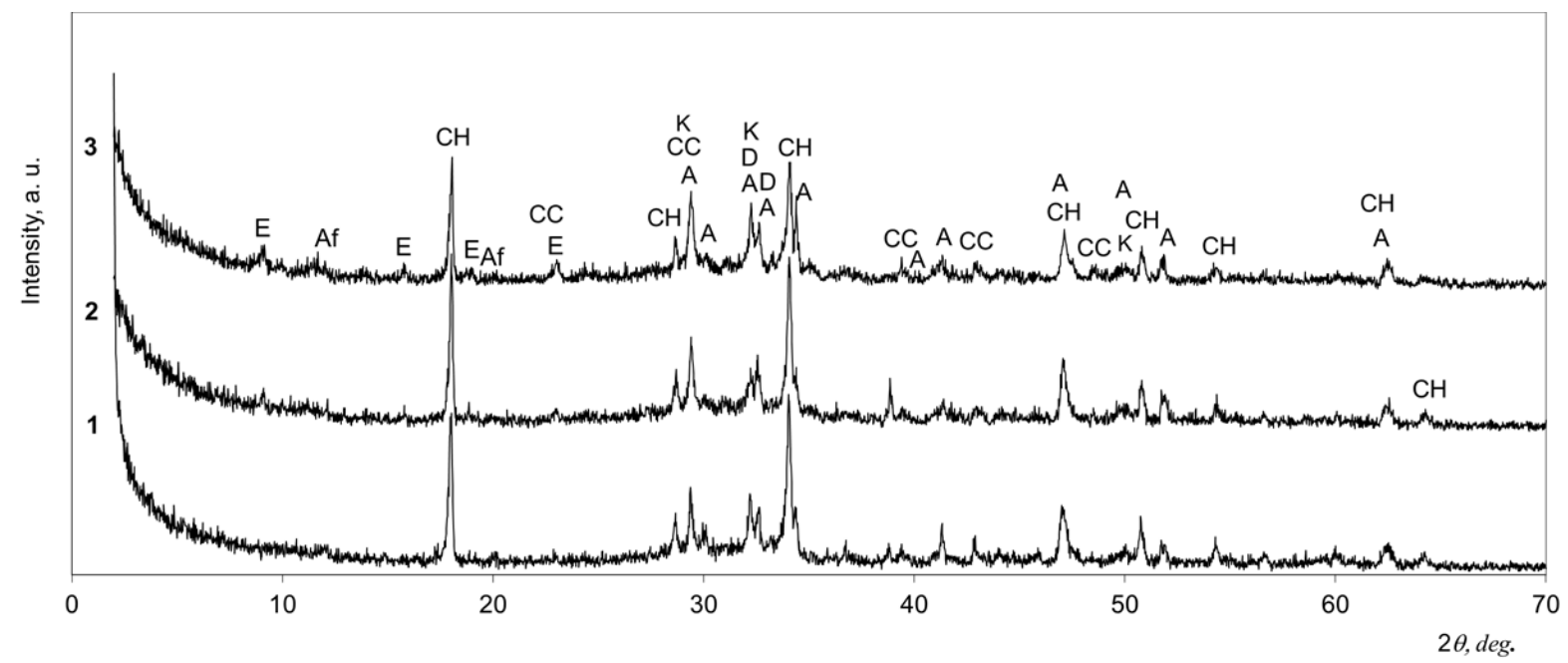

Fig. 5. X-ray diffraction patterns of hardened cement paste, after 28 days. $2 \mathrm{Hs}$ addition content accounts for $0 \%(1) ; 5 \%$ (2); $15 \%$ (3). Notes: $\mathrm{CH}$-portlandite; A-alite; D-belite; $\mathrm{K}$-calcium silicate hydrate; $\mathrm{E}$-ettringite; $\mathrm{CC}$-calcite, Af-monosulfoaluminate



Fig. 6. The thermal analyze of hardened cement paste after 28 days. $2 \mathrm{Hs}$ addition content accounts for $15 \%$



Fig. 7. The dependence of hydration temperature of cement paste on the quantity of $2 \mathrm{Hs}$ additive. Cement paste producing without zeolite and with $5 \%, 10 \%$ and $15 \%$ of $2 \mathrm{Hs}$ 
The increase in specimen strength and the release of higher hydration temperature can also be attributed to active $\mathrm{SiO}_{2}$ and $\mathrm{Al}_{2} \mathrm{O}_{3}$ present in hydrosodalite $(2 \mathrm{Hs}$ additive). Therefore, $2 \mathrm{Hs}$ additive added at $15 \mathrm{wt} \%$ accelerates the hydration reaction (Fig. 7).

\subsection{The comparison of the effect of used additives on cementations systems}

Studies have demonstrated that the three investigated pozzolanic additives - $1 \mathrm{Hs}$, $2 \mathrm{HS}$ and silica fume - have a distinctive influence on the properties of cementations systems. The effect of additives $1 \mathrm{Hs}, 2 \mathrm{Hs}$ had bigger effect on the hydration temperature of the cement paste than silica fume additive (Fig. 4, Fig. 7, Fig. 8). The effect of silica fume on the cement paste hydration temperature influence is insignificant, as can be seen in (Fig. 8).

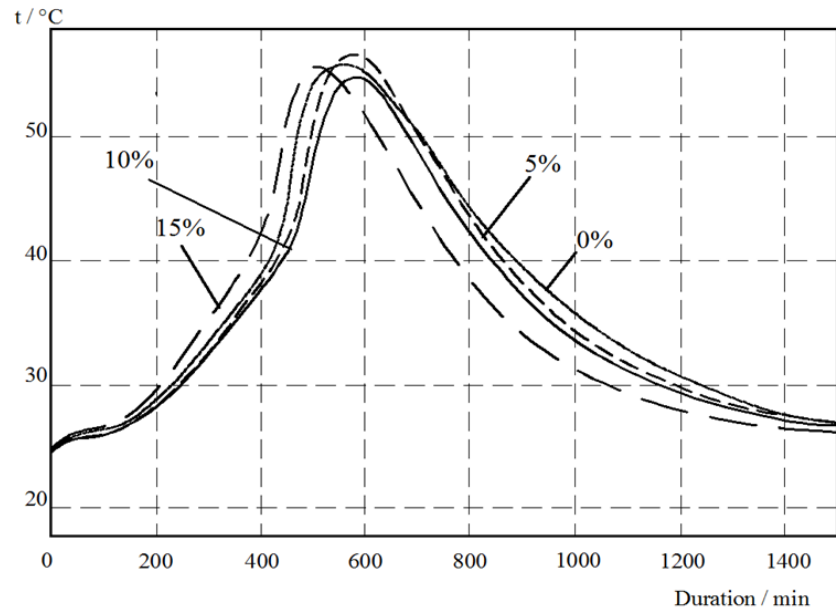

Fig. 8. The dependence function of cement paste hydration temperature on the type of additive after 28 days of hydration. Note $\mathrm{FeSi}$ - silica fume

Specimens with 5 wt.\% $1 \mathrm{Hs}$ additive had the highest compressive strength $(84 \mathrm{MPa})$ under the test conditions. The highest compressive strength was recorded in specimens with $10 \mathrm{wt} . \%$ of $2 \mathrm{Hs}$ additive (101 MPa). The increase in compressive strength may be related to active $\mathrm{SiO}_{2}$ and $\mathrm{Al}_{2} \mathrm{O}_{3}$ present in $1 \mathrm{Hs}$ and $2 \mathrm{Hs}$ additive. The highest compressive strength of $80 \mathrm{MPa}$ after 28 days of hardening was observed in specimens of hardened cement paste with 5 wt. \% silica fume additive.

Higher compressive strength was obtained by using $1 \mathrm{Hs}$ and $2 \mathrm{Hs}$ additives (Fig. 9). Up to $20 \%$ increase in compressive strength of cementitious systems can be achieved by using $2 \mathrm{Hs}$ added at $10 \mathrm{wt} . \%$.

\subsection{Microstructure of hardened cement pastes}

The micro-structural study on hardened cement paste with zeolitic additives revealed that the soluble $\mathrm{SiO}_{2}$ and $\mathrm{Al}_{2} \mathrm{O}_{3}$ could react with $\mathrm{Ca}(\mathrm{OH})_{2}$ to produce calcium silicates hydrate and calcium aluminates hydrate which densified the hardened cement paste matrix.

Pozzolanic effect of these additives improved the microstructure of hardened cement paste and reduced the content of the harmful large pores [11-13]. This is explained by the formation of new crystal and amorphous phases and crystallization of the solution. The majority of new CSH compounds and calcium aluminate hydrate
(AFm) are formed in pores, the number of pores decrease with the crystallization and densification of new compounds. Needle-shaped ettringite, hexagonal laminated crystals of $\mathrm{Ca}(\mathrm{OH})_{2}$, reticulated type crystals of calcium silicate hydrates are seen in SEM images (Fig. 10 a).

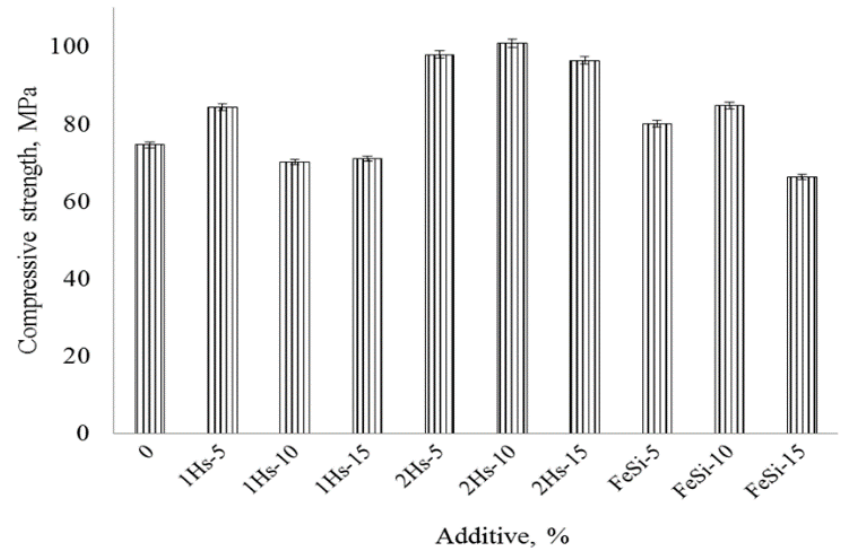

Fig. 9. The dependence of hardened cement paste compressive strength on the type of additive after 28 days of hydration

Newly formed calcium hydro-silicate C-S-H compounds have small needle-shaped crystals seen in SEM image (Fig. $10 \mathrm{~b}, \mathrm{c}$ ). Monosulfoaluminate preparations give apparently single phase preparations with relatively coarse hexagonal plate morphology (see Fig. 10 b, c).

When $15 \mathrm{wt} . \%$ of additive $1 \mathrm{Hs}$ is used, the hexagonal platy AFm phases are about $4.43-3.33 \mu \mathrm{m}$ in size; when additive $2 \mathrm{Hs}$ is used, these platy hexagonal AFm phases are smaller, $1.88-1.51 \mu \mathrm{m}$ in size. Therefore, specimens with $2 \mathrm{Hs}$ additive have smaller surface area.

\section{CONCLUSIONS}

Instrumental analysis has revealed that with higher content of the investigated additives the content of portlandite in the mineral composition of hardened cement paste reduces. According to the thermal analysis results, after 28 days the mass loss in specimens with $1 \mathrm{Hs}$ and $2 \mathrm{Hs}$ due to $\mathrm{Ca}(\mathrm{OH})_{2}$ decomposition is lower by $3.12 \%, 3.16 \%$ respectively compared with the reference specimen $(4.45 \%)$. This decrease in portlandite content can be attributed to the result of pozzolanic reaction. The result is the formation of calcium silicate hydrated $(\mathrm{C}-\mathrm{S}-\mathrm{H})$ phases and aluminates. The highest compressive strengt of $84 \mathrm{MPa}$ is observed in specimens of hardened cement paste with 5 wt. $\%$ of $1 \mathrm{Hs}$ additive, whereas in specimens with 10 wt. $\%$ of $2 \mathrm{Hs}$ additive the highest compressive strength was $101 \mathrm{MPa} .20 \%$ higher compressive strength was reached by using $2 \mathrm{H}_{\mathrm{S}}$ additive. Under the test conditions both $1 \mathrm{Hs}$ and $2 \mathrm{Hs}$ additives accelerate the hydration of the cement paste.

The highest hydration temperature was achieved in a mixture with $5 \mathrm{wt} . \% 1 \mathrm{Hs}$ additive and with $10 \mathrm{wt} . \% 2 \mathrm{Hs}$ additive. The pozzolanic effect of investigated additives $1 \mathrm{Hs}$ and $2 \mathrm{Hs}$ improved the microstructure of hardened cement paste. The formation of additional quantity of small needle-shaped CSH compounds and hexagonal plate monosulfoaluminate hydrate (AFm) phases was observed in the specimens with investigated additives. 




a

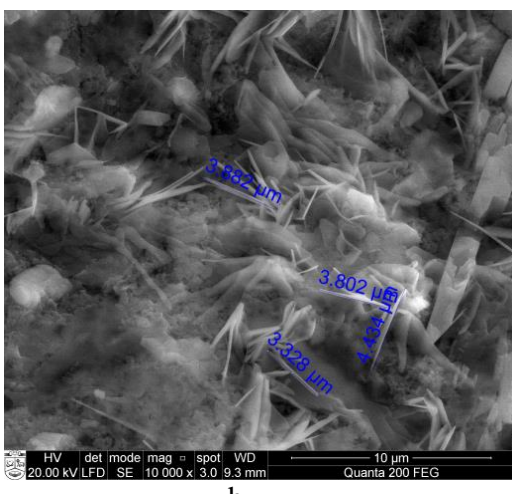

b

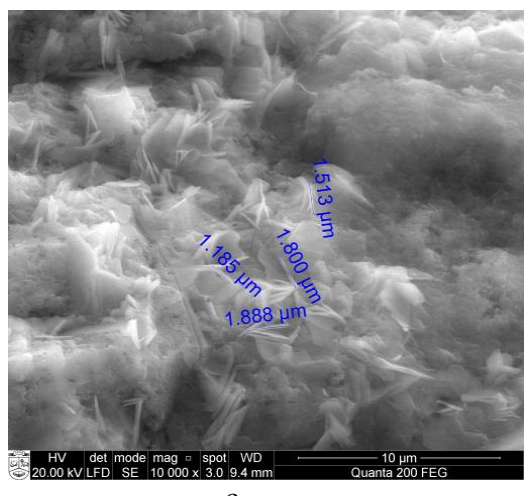

$\mathrm{c}$

Fig. 9. SEM picture of hardened cement paste samples: $a$ - without additives; $b$ - with $15 \%$ of additives $1 \mathrm{Hs} ; \mathrm{c}-2 \mathrm{Hs}$

Results show that, in general, the additive $2 \mathrm{H}_{S}$ is slightly more active as additive $1 \mathrm{H}_{\mathrm{S}}$ or silica fume, although it could be used as a substitute for pozzolans because it has better strength characteristics and is environmentally friendly as well. So, this zeolite could be a good substitute for silica fume.

\section{Acknowledgment}

This work has been supported by the European Social Fund within the project "Development and application of innovative research methods and solutions for traffic structures, vehicles and their flows", project code VP1-3.1ŠMM-08-K-01-020.

\section{REFERECES}

1. Poon, C.-S., Lam, L., Kou, S.-C., Lin Z.-S. A Study on the Hydration Rate of Natural Zeolite Blended Cement Pastes Construction and Building Materials 13 (8) 1999: pp. $427-432$.

2. Chan, Sammy, Y. N., Ji, X. Comparative Study of the Initial Surface Absorption and Chloride Diffusion of High Performance Zeolite, Silica Fume and PFA Concretes Cement and Concrete Composites 21 (4) 1999: pp. $293-300$.

http://dx.doi.org/10.1016/S0958-9465(99)00010-4

3. Lilkov, V., Rostovsky, I., Petrov, O. Physical and Mechanical Characteristics of Cement Mortars and Concretes with Addition of Clinoptilolite from Beli Plast Deposit (Bulgaria), Silica Fume and Fly Ash Clay minerals 46 (2) 2011: pp. 213-223.

4. Lilkov, V., Petrov, O., Petkova, V., Petrova, N., Tzvetanova, Y. Study of the Pozzolanic Activity and Hydration Products of Cement Pastes with Addition of Natural Zeolites Clay minerals 46 (2) 2011: pp. 241-250.

5. Karakurt, C., Topçu, İ.-B. Effect of Blended Cements Produced with Natural Zeolite and Industrial By-Products on Alkali-Silica Reaction and Sulfate Resistance of Concrete Construction and Building Materials 25 (4) 2011: pp. $1789-1795$.
6. Valipour, M., Pargar, F., Shekarchi, M., Khani, S. Comparing a Natural Pozzolan, Zeolite, to Metakaolin and Silica Fume in Terms of their Effect on the Durability Characteristics of Concrete: a Laboratory Study Construction and Building Materials 41 2013: pp. 879-888.

7. Al-Dulaijan, S.-U. Sulfate Resistance of Plain and Blended Cements Exposed to Magnesium Sulfate Solutions Construction and Building Materials 21 (8) 2007: pp.1792-1802.

8. Hekala, E.-E., Kisharb, E., Mostafa, H. Magnesium Sulfate Attack on Hardened Blended Cement Pastes Under Different Circumstances Cement and Concrete Research 32 (9) 2002: pp. 1421 - 1427.

9. Snellings, R., Mertens, G., Cizer, Ö., Elsen, J. Early Age Hydration and Pozzolanic Reaction in Natural Zeolite Blended Cements: Reaction Kinetics and Products by in Situ Synchrotron X-Ray Powder Diffraction Cement and Concrete Research 40 (12) 2010: pp. 1704-1713. http://dx.doi.org/10.1016/j.cemconres.2010.08.012

10. Bondar, D., Lynsdale, C.-J, Milestone, N.-B., Hassani, N., Ramezanianpour, A. A. Effect of Heat Treatment on Reactivity-Strength of Alkali-Activated Natural Pozzolans Construction and Building Materials 25 (10) 2011: pp. $4065-4071$. http://dx.doi.org/10.1016/j.conbuildmat.2011.04.044

11. Karakurt, C., Bekir, L.-T. Effect of Blended Cements Produced with Natural Zeolite and Industrial By-Products on Alkali-Silica Reaction and Sulfate Resistance of Concrete Construction and Building Materials 25 (4) 2011: pp. 1789-1795.

12. Ovcharenko, G.-I., $\quad$ Sviridov, V.-L, $\quad$ Francev, V.-B., Kasanzeva, L.-K. Natural Zeolites - New Row Materials for Building Materials Technology Arhitectural and Construction in Siberia 6 2002: pp. 45-51(in Russian).

13. Perraki, Th., Kakali, G., Kontoleon, F. The Effect of Natural Zeolites on the Early Hydration of Portland Cement Microporous and Mesoporous Materials 61 (1) 2003: pp. $205-212$. 